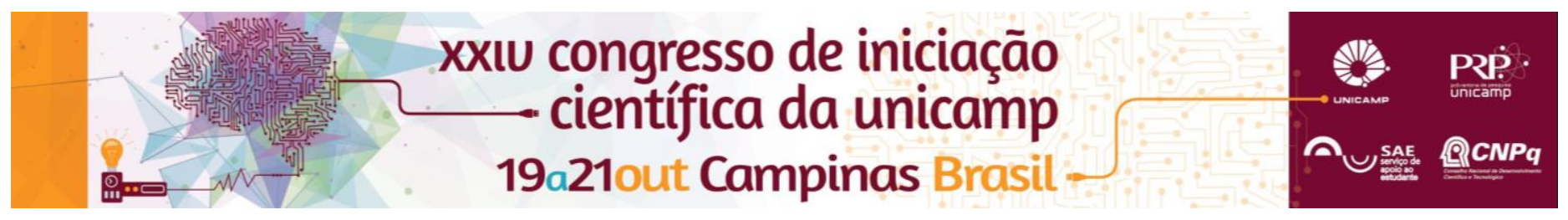

\title{
Hot Spot na análise da expansão da cana-de-açúcar no centro-sul do Brasil.
}

\section{Paulo Renato Lima (IC), Priscila Pereira Coltri (PQ), Andrea Koga Vicente (PQ), Jurandir Zullo Junior (PQ) .}

\section{Resumo}

O trabalho teve como objetivo central avaliar a técnica de análise espacial hot spot para investigar a expansão de canade-açúcar na região Centro-Sul do Brasil. Para tanto, utilizou-se dados georreferenciados de área plantada com canade-açúcar na principal região produtora nacional. Após a análise verificou-se que a maior expansão da cana ocorreu em direção ao oeste do país e a técnica hot spot foi efetiva em capturar o vetor de expansão da fronteira canavieira.

\section{Palavras-chave:}

Palavras Chave: setor sucro-energético, expansão agrícola, técnicas de análise espacial.

\section{Introdução}

O processamento de grade quantidade de informações representa um dos principais desafios para a análise de dados geográficos. Para uma compreensão mais efetiva e, até mesmo, para maior agilidade na resolução dos problemas durante as pesquisas utilizamos plataformas do tipo Sistema de Informações Geográficas (SIG). LOPES (2010) ${ }^{1}$ ressalta a importância dessas plataformas para a manipulação de grandes volumes de dados e ao mesmo tempo a sua integração a gráficos e mapas digitais. Em particular, tal fusão de dados através desses sistemas retrata uma nova leitura dos dados associados à dimensão espaço-tempo.

O presente trabalho analisa a expansão da cana-deaçúcar de 1995 a 2011, na região de maior produção do país que compreende os estados de PR, SP, MG, MS e GO. Essa análise envolve um grande volume de informações que, na maioria das vezes, não podem ser avaliadas de forma individualizada. Nesse sentido, o objetivo do trabalho foi utilizar o estudo da dinâmica da expansão da cana de açúcar na região centro-sul do Brasil para avaliar a técnica de análise espacial hot spotem apresentar os dados e sua evolução ao logo dos anos.

\section{Resultados e Discussão}

Primeiramente foram levantados, para os anos de 1995 a 2011, os dados de área plantada dos estados que compõe a região centro-sul (PR, SP, MG, MS, GO). Com base nesse banco de dados, empregou-se a técnica de análise espacial hot spot. Como resultado principal, foi possível observar o vetor de expansão da cultura em direção à região centro-oeste do Brasil. Esse resultado pode ser observado na figura 1.

Nesta figura, podemos observar que em 1995 o hot spot da área plantada com cana $(99 \%$ de significância estatística) estava concentrado no estado de SP. A técnica retrata a evolução de hot spots em direção oeste nos anos subsequente. A figura 1 apresenta o hot spots dos anos de 1995, 2002, 2007 e 2011.
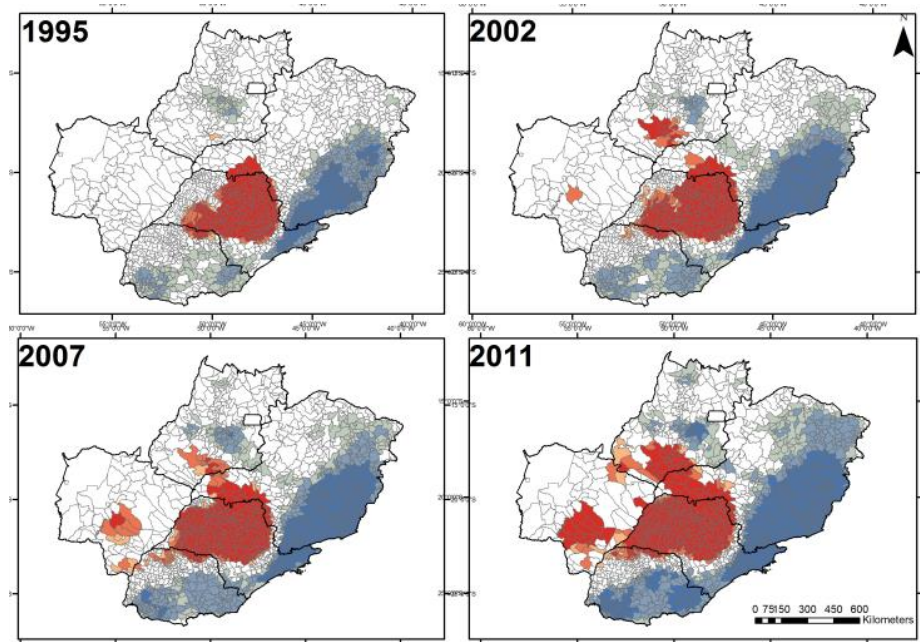

Figura 1. Mapa temático com Hot Spot mostrando a concentração da área plantada de cana-de-açúcar ao longo dos anos de 1995, 2002, 2007 e 2011.

\section{Conclusões}

A técnica hot spot sintetizou o grande volume de informações proporcionando uma análise aprofundada das regiões que se destacaram estatisticamente em relação à área plantada, mostrando, ao longo dos anos, a dinâmica da expansão da cana-de-açúcar.

\section{Agradecimentos}

Os autores agradecem a FAPESP, ao Projeto Alcsens, e ao Serviço de Apoio ao Estudante (SAE)/UNICAMP.

\footnotetext{
1 LOPES, FA \& HELENA, RI. Análise de agravos à saúde e possíveis associações aos produtos da queima de cana-de-açúcar. Coimbra: UC, 2010
} 